\title{
Peer Observation: An Approach to Negotiation Training
}

\author{
D. Lee Warren \\ Belmont University \\ Catherine Loes \\ Belmont University
}

\begin{abstract}
This study considers the use of peer observational learning experiences to improve the teaching of negotiation. The paper examines observational learning in the context of Bandura's Social Cognitive Theory to enhance the efficacy of an observational learning experience. Despite data limitations from a small sample and the use of multiple negotiation exercises, each of these data sources provides some support for the peer observation experience and the use of triangulated data sources to measure this effect. The primary conclusion is that further research is needed to consider how to optimize the learning benefit of the observation exercise.
\end{abstract}

Keywords: Observation, Graduate Education, Negotiation Training, Student Learning, Peer-to-Peer

\section{INTRODUCTION}

The increased recognition of the role of negotiation in business and the consequent necessity to teach business students this skill has created a relatively new "discipline" in many colleges of business. The pedagogy of teaching this important craft has commonly involved both lecture and simulated negotiation activities. The perceived efficacy of simulations as a teaching method in the area of negotiation is documented by their prevalence. [See Fortgang (2000), Williams and Geis (2000) and Druckman and Ebner (2013).] However, more recent studies, such as Alexander and LeBaron (2009) have identified limitations in the methodology and prompted the consideration of additional teaching methodologies.

This paper relies on the Social Cognitive Theory (SCT) presented by Albert Bandura (1986) which highlights the ways in which humans learn from watching, as well as doing. In this context, we examine the effect of students observing the negotiation exercise of their peers on the learning of the observers. The paper begins with a brief discussion of the role of negotiation in business education and the use of simulations in teaching this important tool. The work goes on to summarize the four sub-processes that make up Bandura's SCT and describe their potential application to negotiation observation. The experiment presented compares the negotiation results of observer student pairs and non-observer student pairs. The evaluation is based on both scored outcomes and particular behaviors (Weingart, Hyder and Prietula 1996) established as effective negotiation tactics. The conclusion is that peer observation is beneficial to student learning. The work contributes three ideas to the relevant literature. First, the study is

based on the observation of peers, rather than experts. Second, the study uses multiple forms of data to 
triangulate the assessment of results, which are constrained by the small sample size and the complexity of the chosen negotiation exercise. Third, the study invokes the four subcomponents described in the SCT literature to enhance the efficacy of the observing experience. The primary result is that the subject deserves more study to further examine the SCT sub-processes and their most effective use in negotiation teaching and learning.

\section{Role of Negotiation in Business and Business Education}

Transactions such as purchasing and selling, rights and penalty disputes and clarifying contract terms demonstrate the ubiquitous nature of external negotiation. Internal negotiation is an even more pervasive event. Managers negotiate "up" with bosses, boards and legislators, negotiate "across" with colleagues with whom they share resources and negotiate "down" with subordinates who have their own interests, commitments and power (Lax and Sebeneius 1986). Loewenstein and Thompson (2000) assert the demands of the new economy for management expertise in the area of negotiation, citing the increasingly entrepreneurial nature of working within organizations. Lax and Sebenius (1986) make a compelling argument for the broad applicability of negotiation skills for managers.

"Negotiation is a way of life for managers, whether renting office space, coaxing scarce part from another division, building support for a new marketing plan or working out next year's budget. In these situations, and thousands like them, some interests' conflict. People disagree. And they negotiate to find a form of joint action that seems better to each than the alternative". Lax and Sebenius, 1986, p.1.

In response, managers seek to build their negotiating skills. In a comparison of the "scripts" of novice and trained negotiators, O'Connor and Adams (1999) found that instruction improved negotiation effectiveness. Negotiation training is widely taught in business schools in MBA curricula across the United States. Of the 25 programs listed on the U.S. News and World Report's 2015 ranking of top MBA programs, 20 offer one or more negotiation courses (U.S. News, 2015).

Much of the negotiation training takes place through lecture and simulations. Conley, Tyler and Cukier (2005) identify a multi-step process used in negotiation education that includes both of these pedagogies:

- A lecturer provides and describes some relevant concept;

- Students participate in a practice exercise;

- Students reflect on their performance in the exercise; and

- Students are encouraged to continue the practice and reflection cycle.

This cycle of repeated negotiation practice and reflection leads to learning, as negotiators tend to reach better, more integrative agreements (Thompson 2012) and create more joint gains (Movius 2008) as they participate in more transactions. The widespread use of simulations in the teaching and learning of negotiation evidences the perceived potency of the pedagogy. Fortgang (2000) reports that simulations are a primary negotiation teaching tool among law, business, public policy and planning and international relations disciplines.

However, the use of simulations presents problems as well. Simulations can be a time-consuming practice in which many instructors are not well-trained (Druckman and Ebner 2013). Effective use depends on the engagement of the participants, requiring them to take on artificial roles. Alexander and LeBaron (2009) identify problems with the technique at both ends of a spectrum. Students can exaggerate their characters, undermining the potency of the experience for their colleagues. Alternatively, the artificiality of the exercise prevents participants from connecting to the roles and limits the power of the experience. One possible reason for the lack of effective acquisition of new skills through simulation exercises may be the high emotional and cognitive pressure for the participants during the simulation. The participants require a unique set of skills that need to be present in order to participate in the simulation 
such as, recall facts from the scenario, maintain a prepared strategy, manage new information, control emotions, actively listen, and maintain procedural information.

\section{Social Cognitive Theory}

As an alternative to experiential learning as carried out in simulations, observational learning is a method of learning that occurs by watching others. These observations can occur in a variety of situations from children watching their parents to amateur athletes watching professional athletes or novice thespians watching actors in movies. McKendree, Stenning, Mayes, Lee and Cox (1998) suggest when an individual is able to remove himself from the pressures of performing the cognitive load can be reduced so that "concentration on content and process of what is being said" can benefit the observer (p. 117). Albert Bandura's Social Cognitive Theory (SCT) provides a theoretical foundation for the process behind observational learning. Bandura asserts that "much human learning is aimed at developing cognitive skills on how to gain and use knowledge for future use" and that "virtually all learning phenomena, resulting from direct experience, can occur vicariously by observing other people's behavior and its consequences for them" (Bandura, 1986 p. 8, p. 19).

Observation can be especially effective when one seeks to gain new perspectives or novel behaviors. Further, observational learning allows the observer to cognitively rehearse observed behaviors without the risks associated with direct experiences (Hoover \& Giambatista, 2009) and has significant advantages over more traditional teaching methods such as through simulation (Manz \& Sims, 1981). Specifically, through observation behaviors can be demonstrated instead of having to be written down, and observational learning can be more enjoyable for the learner encouraging greater engagement. "The capacity to learn by observation enables people to acquire rules for generating and regulating behavioral patterns without having to form them gradually by tedious trial and error" (Bandura, 1986 p. 19).

According to Bandura, four sub-processes govern observational learning:

- Attention processes impact what the observer chooses to attend to from the observed activities. Determinants include the "cognitive skills, preconceptions and value preferences of the observers" (Bandura 2001, p. 8).

- Retention processes involve using small segments or codes in transforming information gained from observation into mental concepts that can be accessed at a later time.

- Production processes occur when the observer decodes the information coded in the retention phase and reproduces those coded images into action in a situation more or less like the observed activity.

- Motivational processes divide the actions that are acquired in the retention process into those that will be produced and those that will not. Only those retained behavior that have a positive motivational component (e.g., direct positive impact or alignment with the individual's value system) for the observer (Bandura, 2001).

Attention to these sub-processes holds the key to the effective use of observation pedagogy in teaching negotiation.

\section{Prior Research on the Use of Observational Learning in the Teaching of Negotiation}

In a survey of negotiation training, Conley, Tyler and Cukier (2005) report nine key lessons for negotiation teaching that include techniques such as analogical reasoning and role-plays and they cite observational learning as one of the most effective techniques for teaching negotiation. Exercises have been developed to portray effective negotiations through the use of filmed experts, actors, or clips from movies or TV shows. Video negotiations can be paused and scenes discussed without interrupting the flow of the negotiation.

Bransford and Schwartz (1999) advocate the use of a variety of learning techniques including observational learning to build behavioral and cognitive skills such as those required in negotiation. In an effort to support lasting learning in negotiations, the use of observational learning is a critical component 
according to McAdoo and Manwarning (2009) and Movis (2008). The process of observational learning allows for a subconscious level of knowledge absorption and contemplation often not present in direct experiences (Bransford \& Schwartz, 2001; Conley \& Tyler, 2005; McAdoo \& Manwaring, 2009; Movis, 2008).

Observations can be used as a teaching technique to demonstrate behaviors that occur in a variety of situations both common and novel. Learning can occur "not by learning a new fact which was not known before, but by juxtaposing ideas in a novel way and realizing consequences which hadn't been considered" (McKendree et al, pg. 115). These viewed interactions can be instrumental in the formation of rules and behaviors that can be put into use in future situations. When the learned behavior requires both conceptual and performance skills, the use of observational exercises can increase the speed of learning over that required when actually performing the task (Manz and Sims, 1981). For example, in negotiations these behaviors may include the skill of questioning to uncover shared interests or the process to deal with an unfair opponent.

Based on their review of the literature on teaching negotiation, Nadler, Thompson and Van Boven (2003) identified four common methods for negotiation training: didactic learning, learning via information revelation, analogical learning (simulation) and observational learning. Nadler et al. designed an experiment to compare these four methods. Participants engaged in a negotiation without the benefit of any training; then treatments using each of the four methodologies were administered, one to each participant. Following the learning treatment, the participants engaged in a second, scored negotiation. Both negotiation performance and process evaluation measures were used to determine the effectiveness of the treatments. They documented significant improvement in the negotiation performance of participants who received either the observational or analogical treatment (Nadler et al. 2003). This result supports the continued use of simulations as part of the pedagogical approach to teaching negotiation and recommends the addition of observational learning activities.

In an earlier study Loes and Warren (2016) describe a "fishbowl" exercise in which graduate business students observed expert negotiators in a simulated negotiation. Students reflected on skills they observed and behaviors they planned to emulate in future negotiations. The experience was crafted with particular attention to Bandura's SCT sub-processes. For example, the observation was conducted in a live setting in which students (and their faculty) watched the negotiation (and watched each other watch the negotiation) and had the opportunity to question the experts at the conclusion of the demonstration. In this setting, students were motivated to attend to the exercise by their desire to impress their peers, their teachers and the experts. The results of this study provide support for observational learning. In the class period following the observation, students engaged in a negotiation simulation activity in which they reproduced successful behaviors noted and retained from the observation.

While generally supportive of the benefits of observation, the study's results were limited. First the self-reported data suffers from inherent biases. Second the students often viewed the skills of the expert negotiators far beyond their reach as novice negotiators. Third, a recency effect constrained the long-term impact of the experience; the more chronologically removed students were from the observation, the less significant the experience became.

\section{Peer-to-Peer Observation}

The observation of expert negotiators proved moderately beneficial to the graduate students. However, the learning generated, while positive, was limited. One potential constraint in the learning is that students perceived that the experts were too advanced for their own replication. Bandura (1997) suggests that when the observer perceives a large disparity between himself and the observed, the observer is "likely to view skills exemplified by an experienced model as beyond their reach and are thus disinclined to invest the effort needed to master them fully" (p. 234). This perceived gap could lead to decreased motivation both during the observation and in subsequent applications.

However, Bandura (1977) goes on to offer that "seeing or visualizing people similar to oneself perform successfully typically raises efficacy beliefs in observers that they themselves possess the 
capabilities to master comparable activities" (p. 87). McKendree, et al. suggest when an observer sees a peer manage a challenging situation, it may speed the diffusion of understanding situations.

Brown and Inouye (1978) ideate that when an individual observes someone of perceived comparable ability, the observation is likely to generate a notion of potential success and increase motivation in regard to the task at hand. The observers see their "potential future selves" in the observed experience and are propelled into changing their behavior (Murphey and Arao, 2001). According to Lave and Wenger (1996), "As an aspect of social practice, learning involves the whole person; it implies not only a relation to specific activities, but a relation to social communities - it implies becoming . . . a kind of person" one desires from observing certain behaviors (p. 146-147). Thus, replicating behaviors observed from peers may be more likely than from observing experts.

\section{Use of Peer Observation in Graduate Negotiation Courses at a University}

Negotiation is an elective set of courses in the MBA and Masters of Accountancy (MACC) programs at a mid-size, private university. The set of courses includes an Introductory Negotiation class, a Mediation class and an Advanced Negotiation class. All three classes are based on the "principled negotiation" method used in the Harvard Program on Negotiation. The three classes all use simulation as the primary teaching method.

In this study, faculty provided observational learning opportunities for students in Introductory and Advanced Negotiation classes. Students observed classmates conducting a simulation exercise, in person and real time. In the first five classes of the course, students were randomly selected to observe a simulated negotiation conducted by classmates. (In the second half of the course the remaining students were assigned observation roles so that all students, ultimately, had the opportunity to benefit from the observation experience.) Negotiation simulation exercises consist of two or more roles and focus on specific learning objectives. Each student receives a different role and set of information prior to the negotiation and plays that role during the simulation. The observing students were given all of the roles for the simulation and prior to the observation experience, were required to answer a set of questions regarding behaviors, strategies and tactics they expected to observe during the simulation. After the negotiation, both negotiators and observers completed a reflection highlighting their learning through the exercise. In an attempt to optimize the benefits of the observation, we designed the exercise to include the four sub-processes Bandura described as part of observational learning.

\section{Attention Processes}

Each student enrolled in the negotiation course as an MBA elective, signaling interest in the subject and/or belief that negotiation skills are valuable. Generally, students in our programs are highly motivated to learn applicable business skills. All participants were required to have read each of the roles that were represented in the negotiation exercise and complete a preparation worksheet identifying issues to be decided. The observers also proposed aspects of the simulation they believed might be problematic between the negotiating pairs and co-led the post-negotiation class discussion, specifically showcasing the observer perspective. In this setting, students are motivated to attend to the exercise by their desire to impress their peers, their teachers and the experts.

\section{Retention Processes}

Within 48 hours the students completed a reflection assignment regarding the exercise. Observers were asked to share any information that, having read both sides, they were aware of but was not uncovered in the course of the negotiation and encouraged to consider any viewed actions that they would use in future negotiations. Observers also participated in the "debriefing" process at the conclusion of the exercise forcing them to verbalize their observations. Lincoln and Guba (1985) suggest that peer examination can make explicit ideas that previously remained implicit within the mind of the participant. 


\section{Production Processes}

All students had an opportunity to observe prior to the final negotiation exercise of the term. As a result, all students had a chance to reproduce behaviors they observed and identified as effective. For the observation element, in the midcourse exercises that are the subject of this study, students who had observed peers in person negotiated with other in-person observers. To the extent that the observation experience enhanced their skills, the partners should generate an improved outcome, with a more integrative agreement. The scoreable nature of the exercise provides both feedback on this result to the participants and an objective measure of results for the researchers. All negotiators also had the opportunity to reflect on their own use of these behaviors.

\section{Reinforcement and Motivational Processes}

Students who observed and then ably reproduced the tactics that led to that success, are then motivated to make these practices part of their negotiation skill set. The motivation for the observers included the desire to receive a good grade in the class, desire to learn a new skill for the student's professional career, value of the learning experience, desire to please the instructor, and wanting to been seen as a good negotiator by classmates.

\section{Expectations}

Based on the principles of SCT as well as the literature surrounding the pedagogy of teaching negotiation, the authors posit that carefully constructed peer observation opportunities contribute to negotiation skill development. Observation will both improve the quality of the outcome, as measured by deal scores and increase the presence of effective negotiating behaviors, as measured through frequency metrics.

\section{METHOD}

Two scorable negotiation exercises provide both process and outcome measures. The different exercises are chosen to be appropriate to the skill levels of introductory and advanced negotiation students. In each case, the simulation includes multiple issues to be decided, including distributive, integrative and compatible concerns. Distributive issues are those that are equally important to the negotiators and for which their interests are opposing. Compatible issues are those for which the negotiators have similar desires. Integrative issues are those for which the negotiators want different outcomes and for which they have differing levels of intensity. The "deal" gets bigger (and for scored negotiations the score rises), when negotiators are willing to make concessions on issues that are less important and make firmer demands on issues of less importance. The varying levels of importance create the opportunities for bigger deals. The discovery of these possibilities requires skill in asking effective questions, packaging alternatives and managing concessions.

Two groups of students are considered. One group of students had no peer observation experience of any kind. The second group of students had participated in real-time observation of their peers. Students who had previously observed in person, a peer negotiation, were partnered with other students who had observed and students who had not observed in real time were partnered with similar non-observers. All negotiations were video recorded for the purposes of student reflection and expert evaluation.

Three types of data were collected to evaluate the effect of the observations on the acquisition of negotiation skills. The data include the quantitative score from the negotiation, expert evaluation of the negotiations, and student reflections. The three sets of data are used to increase reliability of the findings and to address the shortcomings of prior studies that relied solely on self-reported information. This triangulated approach enhances the credibility of the findings by balancing the weaknesses of the individual methods and corroborating the information collected (Creswell \& Miller, 2000; Eisenhardt, 1998; Miles \& Huberman, 1994; Ridenour \& Newman, 2008; Yin, 1994).

Each of the sources of data have support from prior research. Scores from a quantitative negotiation have been widely used in negotiation research (e.g., Nadler, et al. 2003). Assessment from two expert 
reviewers of each video recording is described in Rosenstein (2002). Erickson (1992) supports the use of observing video recordings as a method to attempt to "understand events whose structure is too complex to be comprehended all at once, given the limits on human information processing" (p. 208). Drawing from medical educational training, Gaba, Howard, Flanagan, Smith, Fish, and Botney (1998) assert that video tapes of simulated experiences allow for the assessment of both technical skills and behavioral tactics. The technical competencies examined were those outlined by Weingart et al. (1996) and included distributive, integrative and neutral behaviors.

The self-reported reflections from the students were used to add depth to the two other sets of data. These were collected from written reflections on the experience that were completed within 48 hours.

A total of 54 teams participated in the negotiation exercise. Of the 54 pairs, 10 pairs participated in the observation experience in the in person, real time format.

\section{RESULTS}

The first set of data collected are the results from the scoreable negotiations. Two different scorable negotiations were used due to the varying level of student negotiation skills. Students in the first negotiation class participated in a simulation of an interview around the terms of employment. The scoring was symmetric and included eight issues that clearly fell in to the distributive, integrative and compatible categories described above. Students in the advanced negotiation class participated in a conversation between the representatives of an environmental regulatory agency and a pulp producer. Both the issues and the scoring were more complicated. We used the results from the assigned point totals given in the case preparation materials. The negotiating pairs were evaluated as one unit, and the combined scores were tallied. Overall, the results show improved outcome performance for negotiating pairs who had the opportunity to observe themselves and peers.

TABLE 1 SCORING OUTCOMES OF OBSERVERS/NON-OBSERVERS

\begin{tabular}{|l|l|l|}
\hline & First Class & Advanced Class \\
\hline Observers & $10,920(\mathrm{n}=5)$ & $435(\mathrm{n}=5)$ \\
\hline Non-observers & $10,297(\mathrm{n}=37)$ & $355(\mathrm{n}=7)$ \\
\hline
\end{tabular}

The second set of data collected were from faculty evaluating each recording. The faculty used a scoresheet that identified critical and behavioral techniques determined valuable to developing negotiation skills, as presented in Weingart et al. (1996). (Appendix A). The behaviors are grouped into distributive behaviors which tend to focus on one issue at a time and similar to a "split the difference" approach. While these behaviors may lead to an agreement, they typically do not "increase the size of the pie." Integrative behaviors, on the other hand, explore not only individual preferences, but also the strength of those preferences in order to make the biggest deal possible. Table 2 provides these results. Data reported are frequency counts scaled by the length of the negotiation. 
TABLE 2

BEHAVIOR FREQUENCIES PER MINUTE OF NEGOTIATING TIME

\begin{tabular}{|l|l|l|l|l|}
\hline & Distributive & Integrative & Neutral & Total \\
\hline First Class & & & & \\
\hline Observers & 5.4247 & .65568 & 1.09571 & 7.17609 \\
\hline Non-observers & 3.78194 & .83129 & .63968 & 5.25241 \\
\hline Advanced Class & & & & \\
\hline Observers & 1.16558 & 1.30848 & .49955 & 2.97361 \\
\hline Non-observers & 1.32471 & 1.16862 & .33618 & 2.82951 \\
\hline
\end{tabular}

Results are separated into the participants in the first negotiation class and those in the advanced negotiation class. For novice negotiators, the effect of observing their peers prompted increased levels of activity. Measures in both the distributive and neutral categories, as well as the total behaviors per minute, increased for students who had an opportunity to observer their classmates in a negotiation exercise. Give that the experiment was conducted in class six, the results suggest that the observers noted the value of asking more questions and offering more options, but did not distinguish between integrative and distributive behaviors. The results suggest the inexperienced negotiators attended to and retained the observed behaviors but were less precise in producing them, compromising the reinforcement subprocess.

Observers in the advanced negotiation class, with the benefit of significantly more experience, demonstrated more refinement in their behaviors. Those observers increased the number of integrative behaviors per minute of the negotiation, while decreasing the number of distributive behaviors. These results suggest that the advanced negotiators moved through at least three of the SCT subprocesses attending to the effective behaviors, retaining them, and producing them. Their success, as documented by their improved outcome scores, reinforces the use of these behaviors and motivates their ongoing implementation.

The third source of data was student reflections on their learning from the observation experience. These comments were made by students who completed the observation experience prior to the studied exercise and highlight the retention and reinforcement elements of the SCT identified by Bandura. These comments, included in Appendix B, suggest that attention to the observation process can shape the learning that it provides in the context of negotiation. Overall, student comments suggest that observers noted behaviors and tactics used by their peers and were able to effectively reproduce these to their advantage in the scored negotiation. While less authoritative, these comments provide guidance as to the detailed structure of the observation exercise. The directions furnished to support the peer observation can be altered to better focus the efforts of the participants.

All three data sources point to the learning value of the peer observation experience, with more or less reliability. Using the four sub-processes identified in SCT, we can posit explanations for these results:

- Attention: Both novice and advanced observers had the opportunity to review all roles in the exercises they observed. As a consequence, they recognized the extent of information available to the negotiating team if the participants can ask effective questions and explore the responses with care. Both types of attention directing prompt a productive observation experience.

- Retention: At the immediate conclusion of their observation experience, the real time observers led a debrief for the class. This "presentation" required the observers to organize their thoughts about the exercise and to provide feedback to their peers, with the intention to improve peer's performance in future negotiations. Before the next class period, each observer was asked to reflect on behaviors and tactics that had worked and those that were not successful. Both the in-class comments and the written reflections were designed to help students solidify their learning and increase the odds of retaining the benefits of the 
observation experience. Again, both inexperienced and experienced negotiators seemed to effectively retain behaviors they observed to be effective. The advanced negotiators appeared to better refine their retention between distributive and integrative behaviors, while inexperienced negotiators were less refined in the distinction of the observed behaviors.

- Production: The scored negotiation exercise was deliberately chosen because it included enough similarities to observed negotiations that behaviors and tactics that had been observed to be successful were also likely to "work" in the studied exercise. Students who engaged these skills were likely to earn positive results in the form of higher team scores.

- Reinforcement and Motivation: Following the scored negotiation, students participated in a class discussion about their performance, including disclosure of the scored results of each team. After the class period, students completed a written reflection in which they were asked to consider which of their efforts were successful and which were less effective. Students were also asked to discuss how they are using what they are learning in the negotiation course outside of the classroom. This requirement helps students to immediately connect the constructed activities of the academic setting to the "real world." This form of reinforcement has an impact that lasts beyond the formal school term.

\section{Limitations}

This study was based on a small number of graduate business students with varying levels of negotiation experience. The commitment to learn from one's peers may have inhibited the performance of the observed students if the observed students lacked a positive reputation. The differing skill levels of the two groups of students (Introductory and Advanced) necessitated the use of different simulation exercises (New Recruit and DEC vs. Riverside) in order to ensure a level of complexity that was engaging.

Scored negotiation exercises, while useful in quantifying simulation results, limit the kind of negotiations that can be considered. Such negotiations require a set of separate issues that can be packaged in multiple ways into a cohesive deal. This omits a kind of negotiation in which the issues are so intertwined as to be inseparable and disadvantages students for which this is a particular skill.

The students included in the experiment are self-identified as those to whom negotiation is an important skill and do not represent managers more generally. Beyond their interest in negotiation specifically, they are graduate business students in a private higher education institution. While this serves our purposes well in terms of their commitment to the subject matter and to excellent performance generally, it may limit the generalizability of these results.

\section{Future Research}

This study provides further support of the use of observational learning as part of the pedagogy for teaching negotiation and that peer observation is a valuable experience. This result is consistent with the attention sub-process, suggesting that connecting with the observed subjects (as opposed to observing experts) enhances the experience. In this work it appears that observational learning that is carefully structured to capitalize on one or more of the four observational sub-processes identified in Bandura's SCT increases student learning as documented by scorable negotiations, expert evaluation of behaviors, and self-reported data. However, both the number of observations and the strength of the data limit the conclusions that can be drawn.

Future research should examine different types of learning metrics, video recordings, third-party monitoring of exercises and pre/post-tests. In addition, future work should continue to examine the four sub-processes of SCT to maximize the benefit of observational experiences. For example, some aspects of the observation may be best enhanced by particular attention to one or more these sub-processes. Future research should also consider elements of the observation experience that increase its effectiveness such 
as placement in the course, length of the exercise, guidance for specific techniques to pay attention to as part of certain simulations.

Finally, future research should examine the differential benefits of video versus in person observation. In person observers have advantages of prior exposures to all the information provided to all participants. They are free from the preoccupation and potential bias of self-monitoring. On the other hand, video observation allows for significantly more opportunity for all students. It facilitates the sharing of observation by identifying video clips that highlight particular behaviors. Likely both types of observation add value to the learning experience. Future research can help discern how to make the best use of each type of observation.

\section{CONCLUSION}

This study considers the use of peer observational learning experiences to improve the teaching of negotiation. The paper examines observational learning in the context of Bandura's Social Cognitive Theory and uses the four sub-processes identified therein to enhance the efficacy of an observational learning experience. In particular, the study considers the learning benefit of observing peers, rather than experts as used in other studies. Two groups of students were considered: students who participated only in simulation, with no opportunity for peer observations and students who participated in real time, in person observation of their peers engaging in negotiation exercises. The effects were evaluated in three ways: the scorable negotiation results, expert review of the videotaped negotiations and self-reported comments on the observation experience. Despite data limitations from a small sample and the use of multiple negotiation exercises, each of these data sources provides some support for the peer observation experience and the use of triangulated data sources to measure this effect. The primary conclusion is that further research is needed to consider how to optimize the learning benefit of the observation exercise.

\section{REFERENCES}

Alexander, N., \& LeBaron, M. (2009). Death of the role-play, In Rethinking Negotiation Teaching: Innovations for Context and Culture, edited by C. Honeyman, J. Coben, and G. DePalo. (2009), St. Paul, MN: DRI Press.

Bandura, A. (1977). Self-efficacy: Toward a unifying a theory of behavioral change. Psychological Review, 84, 191215.

Bandura, A. (1986). Social Foundations of Thought and Action: A Social Cognitive Theory. Upper Saddle River, NJ: Prentice-Hall.

Bandura, A. (2001). Social Cognitive Theory of Mass Communications, In D. Z. J. Bryant (Ed.), Media effects: Advances in theory and research, pp. 2-27. Hillsdale, NJ: Lawrence Erlbaum.

Bransford, J., \& Schwartz, D. (2001). Rethinking Transfer: A Simple Proposal with Multiple Implications. In A. Iran-Nejad \& P. D. Pearson (Eds.), Review of Research in Education, 24, Washington, D.C.: American Educational Research Association (AERA), 61-100.

Brown, I. Jr., \& Inouye, D. K. (1978). Learned helpless through modeling: The role of perceived similarity in competence. Journal of Personality and Social Psychology, 36.

Conley, Tyler., \& Cukier. (2005). Nine Lessons for Teaching Negotiation Skills. Legal Education Review, 4(15).

Creswell, J., \& Miller, D. (2000). Determining validity in qualitative inquiry. Theory into Practice, 39(2), 124.

Druckman, D., \& Ebner, N. (2013). Games, Claims and New Frames: Rethinking the Use of Simulations in Negotiation Education. Negotiation Journal, 29(1), 61-92.

Eisenhardt, K. (1989). Building theories from case study research. Academy of Management Review, 14(4), 532-550. 
Erickson, F. (1992). The interface between ethnography and microanalysis. In M. D. LeCompte, W. Millroy, \& J. Preissle (Eds.) The handbook of qualitative research in education. San Diego, CA: Academic Press.

Fortgang, R.S. (2000). Taking Stock: An Analysis of Negotiation Pedagogy across Four Professional Fields. Negotiation Journal, 16(4), 325-338.

Gaba, D., Howard, S., Flanagan, B., Smith, B., Fish, K., \& Botney, R. (1998). Assessment of clinical performance during simulated crises using both technical and behavioral ratings. Anesthesiology, 89(1).

Hoover, J., \& Giambatista, R. (2009). Why Have We Neglected Vicarious Experiential Learning, Business. Simulation and Experiential Learning, 36, 35-37.

Lave, J., \& Wenger, E. (1996). Teaching, Learning, in Practice. Mind, Culture, Activity, 3(3).

Lax, D.A., \& Sebenius, J. K. (1986). The Manager as Negotiator. New York: The Free Press.

Lincoln, Y. S., \& Guba, E. G. (1985). Naturalistic inquiry. Newbury Park, CA: Sage Publications.

Loes, C., \& Warren, D. (n.d.). Using Observational Learning to Teach Negotiation. Journal of the Academy of Business Education, 17, 296-310.

Loewenstein, J., \& Thompson, L. (2000). The Challenge of Learning. Negotiation Journal, 16(4), 399408.

Manz, C., \& Sims, H. (1981), Vicarious Learning: The Influence of Modeling on Organizational Behavior. The Academy of Management Review, 6(1), 105-113.

McAdoo, B., \& Manwaring, M. (2009). Teaching for implementation: Designing Negotiation Curricula to Maximize Long-Term Learning. Negotiation Journal, 25(2), 195-215.

McKendree, J., Stenning, K., Mayes, T., Lee. J., \& Cox, R. (1998). Why observing a dialogue may benefit learning. Journal of Computer Assisted Learning, 14, 110-19.

Miles, M., \& Huberman, A. (1994). Qualitative data analysis (2nd ed.). Thousand Oaks, CA. Sage Publishing.

Movius, H. (2008). The Effectiveness of Negotiation Training. Negotiation Journal, 24(4), 509-531.

Murphey, T., \& Arao. (2001, December). Reported Belief Changes through Near Peer Role Modeling. Teaching English as a Second or Foreign Language, 5(3).

Nadler, J., Thompson, L., \& Van Boven, L. (2003). Learning Negotiation Skills: Four Models of Knowledge Creation and Transfer. Management Science, 49(4), 529-540.

O'Connor, K., \& Adams, A. (1999). What Novices Think about Negotiation: A Content Analysis of Scripts. Negotiation Journal, 15(2), 135-147.

Ridenour, C. S., \& Newman, I. (2008). Mixed methods research: Exploring the interactive continuum. Carbondale, IL: Southern Illinois University Press.

Rosenstein, B. (2002). Video use in social science research and program evaluation. International Journal of Qualitative Methods. Creative Commons Attribution License.

Thompson, L. (2012). The Mind and Heart of the Negotiator, $5^{\text {th }}$ ed. Upper Saddle River, NJ: Pearson Education, In. publishing as Prentice Hall.

U.S. News \& World Report. (2015). Retrieved from http://gradschools.usnews.rankingsandreviews.com/best-graduate-schools/top-businessschools/mba-rankings.

Weingart L. R., Hyder, E. B., \& Prietula, M. J. (1996). Knowledge Matters: The Effect of Tactical Descriptions of Negotiation Behavior and Outcome. Journal of Personality and Social Psychology, 70(6), 1205-1217.

Williams G., \& Geis, J. (200). Negotiation Skills Training in the Law School Curriculum., In Teaching Negotiation: Ideas and Innovations, edited by M. Wheeler. Cambridge, MA: PON books, (2000).

Yin, R. K. (1994). Case study research: Design and methods (2nd ed.). Newbury Park, CA: Sage Publications. 


\section{APPENDICES}

\section{APPENDIX A \\ BEHAVIORAL CODING CATEGORIES}

\begin{tabular}{|c|c|c|}
\hline Distributive & & \\
\hline$\overline{\text { Offers }}$ & Single-issue offers & Make an offer on one issue \\
\hline \multirow[t]{2}{*}{$\begin{array}{l}\text { Information } \\
\text { provision }\end{array}$} & Info preferences & State preferred level within an issue \\
\hline & Substantiation & $\begin{array}{l}\text { Make arguments for own position, arguments against } \\
\text { other's }\end{array}$ \\
\hline \multirow[t]{2}{*}{ Questions } & Question preferences & Ask for preferred level within an issue \\
\hline & Question substantiation & Question the arguments presented \\
\hline \multirow[t]{2}{*}{$\begin{array}{l}\text { Procedural } \\
\text { comments }\end{array}$} & $\begin{array}{l}\text { Procedures related to } \\
\text { one issue }\end{array}$ & Suggest addressing one issue at a time \\
\hline & $\begin{array}{l}\text { Procedures related to } \\
\text { compromise }\end{array}$ & $\begin{array}{l}\text { Suggest a compromise or willingness to concede on an } \\
\text { issue }\end{array}$ \\
\hline \multicolumn{3}{|l|}{ Integrative } \\
\hline$\overline{\text { Offers }}$ & Multi-issue offers & Make an offer on two or more issues under discussion \\
\hline $\begin{array}{l}\text { Information } \\
\text { provision }\end{array}$ & Info priorities & State which issues are more or less important to oneself \\
\hline Questions & Question priorities & $\begin{array}{l}\text { Ask which issues are more or less important to other } \\
\text { party }\end{array}$ \\
\hline \multirow[t]{2}{*}{$\begin{array}{l}\text { Procedural } \\
\text { comments }\end{array}$} & $\begin{array}{l}\text { Procedures related to } \\
\text { package }\end{array}$ & $\begin{array}{l}\text { Suggest discussion of two or more issues at the same } \\
\text { time }\end{array}$ \\
\hline & $\begin{array}{l}\text { Procedures related to } \\
\text { reciprocity }\end{array}$ & $\begin{array}{l}\text { Suggest a concession to be made in exchange for an } \\
\text { unidentified future concession }\end{array}$ \\
\hline \multicolumn{3}{|l|}{ Neutral } \\
\hline & Positive reactions & Positive reactions \\
\hline & Miscellaneous & $\begin{array}{l}\text { Off-task and low frequency comments (negative } \\
\text { reactions, mutuality and summarization }\end{array}$ \\
\hline
\end{tabular}

From Weingart, Hyder and Prietula (1996) P. 1217 


\section{APPENDIX B \\ STUDENT COMMENTS WITH REGARD TO OBSERVATION}

What behavior did you observe that you will add to your negotiation strategies going forward? (Production)

- I will try not to be hung up on one point that seems to be getting me nowhere.

- I really liked how Alex and Shatia went about breaking down their interests into smaller batches in order of importance. When I read this case, I felt like that many issues were overwhelming.

- I liked Jake's thorough introduction and process planning. It was a nice reminder of how being well prepared can make a difference in both setting a positive town and ensuring that time is well spent.

What was most valuable about the observation experience? (Reinforcement and Motivation)

- Always make sure the process is perceived as fair. At that point, even if neither party wins or one party loses, the losing party doesn't feel neglected or used.

- There is definitely more involved in using persuasion that just using words. The tone of someone's voice, his hand gestures, body language and eye contact all have an effect.

- The most valuable thing about the observation experience was being in the position to see all sides of the situation. In that space you are able to better see what is being done well and the facts that may have been left on the table. Once you have identified the pieces that were left untouched you reflect on why and apply those strategies to your own negotiation techniques. 